\title{
Equifinality and multifinality in developmental psychopathology
}

\author{
DANTE CICCHETTI AND FRED A. ROGOSCH \\ Mt. Hope Family Center, University of Rochester
}

Since its inception as an emergent interdisciplinary science, diversity in process and outcome have been conceived as among the hallmarks of the developmental psychopathology perspective (Cicchetti, 1984, 1990; Garmezy \& Streitman, 1974; Kohlberg, LaCrosse, \& Ricks, 1972; Sameroff, 1989; Sroufe, 1986, 1989; Sroufe \& Rutter, 1984). Thus, developmental psychopathologists have articulated the expectations that there are multiple contributors to adaptive or maladaptive outcomes in any individual, that these factors and their relative contributions vary among individuals, and that there are myriad pathways to any particular manifestation of adaptive or disordered behavior (Cicchetti, 1993; Richters \& Cicchetti, 1993; Robins, 1966; Robins \& Rutter, 1990; Rutter, 1989, 1995; Sroufe \& Jacobvitz, 1989). Additionally, it is believed that there is heterogeneity among individuals who develop a specific disorder with respect to the features of their disturbance, as well as among individuals who evidence maladaptation but who do not develop a disorder. In accord with this view, the principles of equifinality and multifinality derived from general systems theory (von Bertalanffy, 1968) are germane.

Equifinality refers to the observation that in any open system (cf. Mayr, 1964, 1988) a diversity of pathways, including chance events or what biologists refer to as nonlinear

Address correspondence to: Dr. Dante Cicchetti or Dr. Fred A. Rogosch, Mt. Hope Family Center, Univ. of Rochester, 187 Edinburgh St., Rochester, NY 14608. epigenesis, may lead to the same outcome. Stated differently, in an open system (i.e., one where there is maintenance in change, dynamic order of processes, organization, selfregulation, etc.) the same end state may be reached from a variety of different initial conditions and through different processes. This is referred to as equifinality, an organismic process that possesses significant implications for psychological and biological regulatory systems (Cicchetti, 1996) and for behavioral and biological plasticity (Cicchetti \& Tucker, 1994b). In contrast, in a closed system the end state is inextricably linked to and determined by the initial conditions: if either the conditions change or the processes are modified, then the end state will also be modified (von Bertalanffy, 1968).

Initial descriptions of equifinality emanated from work in embryology. For example, the development of a normal organism was shown to occur from a whole ovum, a divided ovum, or two fused ova. Further, it was demonstrated that different initial sizes and different courses of growth can eventuate in the same ultimate size of an organism (von Bertalanffy, 1968; Waddington, 1957). Within the discipline of developmental psychopathology, equifinality has been invoked to explain why a variety of developmental pathways may eventuate in a given outcome, rather than expecting a singular primary pathway to the adaptive or maladaptive outcome.

The principle of multifinality (Wilden, 1980) suggests that any one component may function differently depending on the organi- 
zation of the system in which it operates. Multifinality states that the effect on functioning of any one component's value may vary in different systems. Actual effects will depend on the conditions set by the values of additional components with which it is structurally linked. Consequently, the pathology or health of a system must be identified in terms of how adequately its essential functions are maintained. Stated differently, a particular adverse event should not necessarily be seen as leading to the same psychopathological or nonpsychopathological outcome in every individual. Likewise, individuals may begin on the same major pathway and, as a function of their subsequent "choices," exhibit very different patterns of adaptation or maladaptation (Cicchetti \& Tucker, 1994a; Rutter, 1989; Sroufe, 1989; Sroufe, Egeland, \& Kreutzer, 1990).

The collection of papers in this Special Issue represents a diversity of approaches to studying pathways conceptualizations in developmental psychopathology. Many of the papers involve the presentation of longitudinal data to delineate various patterns of functioning over time and differential processes contributing to outcomes. Developmental periods ranging from infancy to very old age are examined, and a plethora of types of psychopathological outcomes, including early disruptive behavior, conduct disorder and antisociality, depressive and anxiety disorders, substance and alcohol disorders, and schizophrenia are investigated, as well as a variety of personality functioning and coping dimensions. Psychological and biological processes and their interplay in development are elucidated to provide integrative conceptualizations of the developmental course.

Beyond this broad scope of populations, developmental periods, psychopathologies, and contributory processes, the papers in this Special Issue share a number of important commonalities. In examining developmental pathways, the contributors were asked to address how their work could be used to illustrate issues of equifinality and/or multifinality in their respective papers. Thus, the goal of the contributors was to examine diversity in origins and processes leading to common outcomes, as well as to elucidate processes con- tributing to divergence in outcomes given common origins. In many respects, the strategies needed to achieve these goals run counter to prevailing variable-oriented strategies that strive to identify the primary or major causal agents involved in understanding the etiology of psychopathological conditions. Such variable-oriented approaches are important for understanding the average or most expected outcomes and various component processes that contribute to those outcomes on a group level. These types of analyses may be thought of as a first generation approach that establishes important relations among variables that are prominent in populations. In some areas of inquiry (e.g., conduct disorder, depression) a substantial knowledge base has been accrued in this manner. In contrast, a pathways approach builds upon knowledge gained from variable-oriented studies; however, attention is shifted to exploring the common and the uncommon outcomes, as well as alternate routes by which outcomes are achieved by different individuals (cf. Cicchetti \& Schneider-Rosen, 1986). Thus, what might be considered error variance at the group level must be critically examined for understanding diversity in process and outcome. This more person-oriented level of analysis of a differential pathways approach is vital for achieving a primary mission of developmental psychopathology, implied in its definition as "... the study of the origins and course of individual patterns of behavional maladaptation ..." (Sroufe \& Rutter, 1984, p. 18).

In this Special Issue variable-oriented and person-oriented analyses are presented, with some papers incorporating both types of perspectives. In several behavior-genetic investigations, twin study methodologies are used to obtain population-level estimates of the contributions of genetic and environmental sources of influence. Pathways thinking has stimulated researchers in this area to begin to ask how these types of analyses can impart knowledge of development at the individual level. In many of the papers in this Special Issue, attention to homogeneous subgroups is utilized as a critical strategy for clucidating diversity in process and outcome. The emphasis on subgroup analysis highlights the transi- 
tion from a focus on variables to a focus on individuals, and this transition is essential for demonstrating equifinality and multifinality in the developmental course. The examination of patterns of commonality within relatively homogeneous subgroups of individuals and concomitant similarity in profiles of contributory processes becomes an important data analytic strategy. Moreover, the need to examine the totality of attributes, psychopathological conditions, and risk and protective processes in the context of each other rather than in isolation is seen as crucial for understanding the course of development taken by individuals. For example, the presence of a childhood depressive disorder has different developmental implications depending on whether it occurs alone or in conjunction with conduct disorder. Similarly, the nature of alcoholism varies considerably depending on differences in the life course of antisociality. Thus, this orientation highlights the importance of an organizational view of development (cf. Cicchetti, 1993; Cicchetti \& Sroufe, 1978; Sroufe et al., 1990; Waters \& Sroufe, 1983). The meaning of any one attribute, process, or psychopathological condition needs to be considered in light of the complex matrix of individual characteristics, experiences, and social-contextual influences involved, the timing of events and experiences, and the developmental history of the individual.

\section{References}

Cicchetti, D. (1984). The emergence of developmental psychopathology. Child Development, 55, 1-7.

Cicchetti, D. (1990). An historical perspective on the discipline of developmental psychopathology. In J. Rolf, A. Masten, D. Cicchetti, K. Neuchterlein, \& S. Weintraub (Eds.), Risk and protective factors in the development of psychopathology (pp. 2-28). New York: Cambridge University Press.

Cicchetti, D. (1993). Developmental psychopathology: Reactions, reflections, projections. Developmental Review, 13, 471-502.

Cicchetti, D. (Ed.). (1996). Special issue: Regulatory processes. Development and Psychopathology, 8(1), 1305.

Cicchetti, D., \& Schneider-Rosen, K. (1986). An organizational approach to childhood depression. In M. Rutter, C. Izard, \& P. Read (Eds.), Depression in young people, clinical and developmental perspectives (pp. 71-134). New York: Guilford.

Cicchetti, D., \& Sroufe, L. A. (1978). An organizational view of affect: Illustration from the study of Down's
This attention to diversity in origins, processes, and outcomes in understanding developmental pathways does not suggest that prediction is futile as a result of the many potential individual patterns of adaptation (Sroufe, 1989). There are constraints on how much diversity is possible, and not all outcomes are equally likely (Cicchetti \& Tucker, 1994a; Sroufe et al., 1990). Nonetheless, the appreciation of equifinality and multifinality in development encourages theorists and researchers to entertain more complex and varied approaches to how they conceptualize and investigate development and psychopathology. We believe that the papers in this Special Issue will stimulate researchers to move beyond the use of equifinality and multifinality in post hoc discussions of their findings. Researchers should increasingly strive to demonstrate the multiplicity of processes and outcomes that may be articulated at the individual, person-oriented level within existing longitudinal data sets. Ultimately, future endeavors must conceptualize and design research at the outset with these differential pathways concepts as a foundation. In so doing, progress toward achieving the unique goals of developmental psychopathology to explain the development of individual patterns of adaptation and maladaptation will be realized.

syndrome infants. In M. Lewis \& L. Rosenblum (Eds.), The Development of Affect (pp. 309-350). New York: Plenum Press.

Cicchetti, D., \& Tucker, D. (1994a). Development and self-regulatory structures of the mind. Development and Psychopathology, 6, 533-549.

Cicchetti, D., \& Tucker, D. (Eds.). (1994b). Special issue: Neural plasticity, sensitive periods, and psychopathology. Development and Psychopathology; 6(4), 531814.

Kohlberg, L., LaCrosse, J., \& Ricks, D. (1972). The predictability of adult mental health from childhood behavior, In B. Wolman (Ed.), Mamual of Child Psychopathology (pp. 1217-1284). New York: McGraw-Hill.

Garmezy, N., \& Streitman, S. (1974). Children at risk: The search for antecedents to schizophrenia. Part I: Conceptual models and research methods. Schizophrenia Bulletin, 8, 14-90.

Mayr, E. (1964). The evolution of living systems. Proceedings of the National Academy of Sciences, 51, 934-941. 
Mayr, E. (1988). Toward a new philosophy of biology Cambridge, MA: Harvard University Press.

Richters, J. E., \& Cicchetti, D. (1993). Mark Twain meets DSM-IIl-R: Conduct disorder, development, and the concept of harmful dysfunction. Development and Psychopathology, 5, 5-29.

Robins, L. (1966). Deviant children grown up. Baltimore: Williams \& Williams.

Robins, L., \& Rutter, M. (Eds.). (1990). Straight and devious pathways from childhood to adulhood. New York: Cambridge University Press.

Rutter, M. (1989). Pathways from childhood to adult life. Journal of Child Psychology and Psychiosn, 30. $23-51$.

Rutter, M. (1995). Relationships between mental disorders in childhood and adulthood. Acta Psychiastica Scandinavica, 91, 73-85.

Sameroff, A. (1989). Models of developmental regulation: The environtype. In D. Cicchetti (Ed.), The emergence of discipline, Rochester symposium on developmental psychopathology (Vol. I. pp. 41-68). Hillsdale, NJ: Erlbaum.

Sroufe, L. A. (1986). Bowlby's contribution to psychoanalytic theory and developmental psychology; Attachment: Separation: Loss. Joumal of Child Psychology and Psychiatry, 27, 841-849.
Sroufe, L. A. (1989). Psychopathalogy as developmental deviation. In D. Cicchetti (Ed.). Rischester symposium on developmental psychopulhology: lol. I: The Emergence of a discipline (pp. 13-i0). Hillsdale, NJ: Erlbaum.

Sroufe. L. A., Egeland. B.. \& Kreutzer. T. (1990). The fate of early experience following developmental change: Longitudinal appraiches to individual adaptation in childhexd. Child Detelopment. 61. 13631373.

Smufe, L. A.. \& Jacobvitz. D. (1989). Diverging pathways, detelopmental transfomations, multiple etiologies and the problem of continuity in development. Human Development. 32. 196-203.

Sroufe, L. A.. \& Rutter, M. (1984). The domain of developmental pis'chopathology. Child Development. 55. 17-29.

von Benalanffy. L. (1968). General system theon: New York: Braziller.

Waddington, C. H. (1957). The strategy of genes. London: Allen and Lnwin.

Waters, E. \& Sroufe. L. A. (1983). Competence as a developmental construct. Developmental Review: 3. 79-97.

Wilden, A. (1980). Syistem and structure. London: Tavistock. 